\title{
Stage IV Chronic Lymphocytic Leukemia
}

National Cancer Institute

\section{Source}

National Cancer Institute. Stage IV Chronic Lymphocytic Leukemia. NCI Thesaurus. Code C8646.

Risk: High; Findings: Lymphocytosis and platelets less than 100,000/microliter; Survival (months): 30. (from AJCC 8th Ed.) 